\title{
Predicting value of five anthropometric measures in metabolic syndrome among Jiangsu Province, China
}

Ting $\operatorname{Tian}^{\dagger}$, Jingxian Zhang ${ }^{\dagger}$, Qianrang Zhu, Wei Xie, Yuanyuan Wang and Yue Dai

\begin{abstract}
Background: Metabolic syndrome (MetS), a condition of metabolic disorders, is now causing large disease burden around the world. This study aimed to update the prevalence of MetS in Jiangsu Province of China and evaluate the predicting value of five anthropometric measures including waist circumference $(\mathrm{WC})$, body mass index (BMI), waist-to-height ratio (WHtR), a body shape index (ABSI) and body roundness index (BRI) in MetS.

Methods: 8040 participants from 12 survey sites were enrolled into this cross-sectional study by multi-stage stratified cluster random sampling method from 2014 nutrition and diet investigation project in Jiangsu Province. The transformation of sex-specific z-score made the comparison meaningful when conducting the logistic analysis between anthropometric indices and MetS. The abilities of anthropometric indices to predict MetS were evaluated by the receiver operating characteristic curve (ROC). Delong test was applied to compare area under different ROC curves.
\end{abstract}

Results: The prevalence of MetS in Jiangsu Province was 35.2\% and the standardized prevalence was 34.8\%. WC, BMI, WHtR, ABSI and BRI z-scores were positively related to MetS and its components. WC, WHtR and BRI z-score had stronger associations with MetS than BMI and ABSI in both male and female population. WC, WHtR and BRI had larger area under ROC curve than BMI and ABSI in male and female. WC in men had the largest area under the ROC curve, significantly higher than the other four measures of BMI, WHtR, ABSI and BRI ( $Z$ value $=9.08,2.88,16.73$, 2.75 respectively). Among women, WC, WHtR and BRI had larger area under the ROC curve than BMI and ABSI, but the area under the WC, WHtR and BRI curve were not significantly different after the pairwise comparison by the Delong test. The optimal cut-off values of WC, WHtR and BRI for predicting MetS was $85.25 \mathrm{~cm}, 0.52$ and 3.61 in male, $80.05 \mathrm{~cm}, 0.51$ and 3.83 in female.

Conclusion: MetS has become one of the major chronic diseases in Jiangsu Province. WC was better than other four indices in predicting MetS among male population in Jiangsu. WC, WHtR and BRI had superior abilities than BMI/ABSI in predicting MetS among female population.

Keywords: Metabolic syndrome, Waist circumference, WHtR, ABSI, BRI

\footnotetext{
*Correspondence: jscdc002@163.com

${ }^{\dagger}$ Ting Tian and Jingxian Zhang contributed equally to this work.

Institute of Food Safety and Assessment, Jiangsu Provincial Center for Disease Control and Prevention, No.172 Jiangsu Road, Nanjing 210009, Jiangsu, China
}

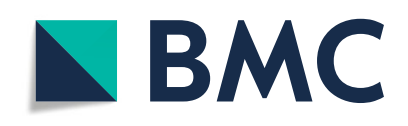

(๑) The Author(s). 2020 Open Access This article is licensed under a Creative Commons Attribution 4.0 International License, which permits use, sharing, adaptation, distribution and reproduction in any medium or format, as long as you give appropriate credit to the original author(s) and the source, provide a link to the Creative Commons licence, and indicate if changes were made. The images or other third party material in this article are included in the article's Creative Commons licence, unless indicated otherwise in a credit line to the material. If material is not included in the article's Creative Commons licence and your intended use is not permitted by statutory regulation or exceeds the permitted use, you will need to obtain permission directly from the copyright holder. To view a copy of this licence, visit http://creativecommons.org/licenses/by/4.0/. The Creative Commons Public Domain Dedication waiver (http://creativecommons.org/publicdomain/zero/1.0/) applies to the data made available in this article, unless otherwise stated in a credit line to the data. 


\section{Background}

Metabolic syndrome (MetS) is a group of metabolic disorders including obesity, elevated blood glucose, dyslipidemia and high blood pressure [1]. Additional energy intake and sedentary lifestyle caused the accumulation of central and visceral fats, further developing the abnormity of metabolism [2]. Furthermore, MetS is a crucial multiplex risk factor of cardiovascular diseases and type 2 diabetes [3]. Results from a study demonstrates that patients with MetS have a two-fold increased risk of cardiovascular disease and a five-fold increased risk of type 2 diabetes [4].

MetS is at a high prevalence level around the world. United States National Health and Nutrition Survey revealed that more than one-third US adults had MetS [3]. The trend of MetS in developing countries is also gradually rising. According to Chinese national surveillance data in 2010, the prevalence of MetS among adults in mainland China were $33.9 \%$. As for Jiangsu Province in eastern China, the most recent prevalence of MetS was 32.7\% surveyed in 2010. With the great changes of lifestyle and dietary habits, the update of MetS condition in this region is urgently needed.

Early identification and intervention of at-risk subjects can prevent the ongoing of MetS and control the progression to other chronic diseases, which will bring lots of benefits to human health and reduce the individual and societal burden of related diseases. In view of the above reasons, there are a rising number of anthropometric indicators applied to predict MetS. This study chose non-invasive, low-cost and easilycalculated measures, including waist circumference (WC), body mass index (BMI), waist-to-height ratio (WHtR) [5], a body shape index (ABSI) [6], and body roundness index (BRI) [7] and compared their abilities in predicting MetS.

Obesity condition was represented by WC and BMI. WC is a simple, inexpensive method to measure central obesity [8]. WHtR has been shown to be associated with obesity-related diseases [9]. The use of WHtR as a better predictor of CVD risk factor has been supported by Meta-analysis [10]. ABSI invented by Krakauer et al. was firstly used in the prediction of death risk [6]. A related research illuminated that there was significant association between ABSI and central obesity, besides, it was better than BMI in the prediction of type 2 diabetes [11]. BRI was created by Thomas et al. for measuring the association with visceral fat accumulation at the first time [7]. The study in Peruvian adults found that BRI had clinical diagnostic value in predicting MetS [12]. As time went on, the application of these indices has been further extended and researchers have exerted tremendous fascination on exploring the association between these indicators and MetS components. It seems that using these widely-used and easily-calculated anthropometric measures are promising in predicting MetS.

Up to now, there are some relevant researches comparing the predicting value of several anthropometric indicators in MetS among Chinese population, however, the study subjects are either from a single center [5] or a small sample size [13]. Therefore, this study selected regional representative samples through scientific sampling methods, aiming to update the prevalence of MetS and its components in Jiangsu Province and find out the potential regional representative anthropometric indicators in predicting MetS among adults based on 2014 nutrition and diet investigation project in Jiangsu Province.

\section{Methods \\ Participants}

This was a cross-sectional study consistent with checklist of items in STROBE statement (seen in Additional file 1) and the investigation was based on the 2014 nutrition and diet investigation project in Jiangsu Province of eastern China. Participants were recruited representatively by multi-stage stratified cluster sample method from September to November in 2014. In the first stage, by the method of systematic sampling, the survey counties (districts) were selected as the survey sites in rural or urban areas. In the whole province, 12 areas, Jiangyin, Changshu, Taicang, Jurong, Jianye, Qinhuai, Haimen, Dafeng, Sihong, Quanshan, Suining and Tongshan, were selected as the survey sites. In the second stage, 3 townships/streets (a city administrative area at the same level as the township in China) were randomly chosen at each survey site. In the third stage, 2 villages/neighborhood committee were randomly selected at each township/street. In the fourth stage, 75 households were randomly selected from each village/neighborhood committee. All the adult family members in the household, who aged over 18 years old, were enrolled in this investigation. If the participants refused to be investigated, then the corresponding number of substitutes were chosen at the same survey site. A total of 8805 individuals were investigated, 765 individuals were excluded because of missing key information, and finally 8040 individuals were included. Smoking/Drinking was defined as those who were existing smoke/drink habits at the survey time. 


\section{Data collection}

Epidemiological survey: The structured questionnaire was administered to collect the basic information (age, gender, education level, smoking history and drinking history). Hypertension, diabetes, dyslipidemia and family history of the respondents were interviewed by the unified trained investigators.

Physical examination: After the interview, the height, weight, waist circumference and blood pressure were measured by the investigators. Height was measured once in centimeter $(\mathrm{cm})$; weight was measured once in kilogram $(\mathrm{kg})$. Waist circumference and blood pressure were measured in a standard protocol [14]. When measuring WC by trained investigators, the participants were required to stand upright, relax their abdomen, naturally droop their arms, and put their feet together (both legs were loaded). The measuring point of $\mathrm{WC}$ was at the middle point between the bottom of the rib cage and the uppermost border of the iliac crests at the end of exhalation in standing positions with an inelastic tape [11]. The soft ruler was moderately tightened, then mark the measuring points on both sides, repeat the measurement twice, and record the average value in precision of $0.1 \mathrm{~cm}$. Blood pressure (BP) was measured three times. BP was measured by the standard mercury sphygmomanometer and the unit was millimeter mercury $(\mathrm{mmHg})$. After 5 min' sedentary seat, first measurement was taken by the trained investigators. In total, three measurements were performed, and one minute between each measurement. The three measurements were averaged as the blood pressure values of the individual. Kept one decimal place for all measurement results.

Laboratory examination: $5 \mathrm{ml}$ of fasting venous blood was collected in the morning to measure level of triglyceride, high-density lipoprotein and fasting plasma glucose (FPG).

Strict quality control was implemented throughout the investigation and laboratory examination.

\section{Diagnostic criteria for MetS}

The diagnostic criteria for the MetS and its components in the Chinese population were based on the 2009 Joint Interim Statement (JIS) [15], (1) Central obesity: male/female's waist circumference $\geq 85 / 80$ $\mathrm{cm}$; (2) Elevated triglycerides: $\mathrm{TG}>1.70 \mathrm{mmol} / \mathrm{L}$ or those who received drug treatment for hypertriglyceridemia; (3) Reduced HDL-C: male/female's HDL$\mathrm{C}<1.0 \mathrm{mmol} / \mathrm{L} / 1.30 \mathrm{mmol} / \mathrm{L}$ or those who treated for reduced HDL-C; (4) Elevated blood pressure: systolic blood pressure (SBP) / diastolic blood pressure (DBP) $\geq 130 / 85 \mathrm{mmHg}$ or those who were treated with hypotensive therapy; (5) Elevated fasting glucose: $\mathrm{FPG} \geq 5.6 \mathrm{mmol} / \mathrm{L}$ or those who received anti-hyperglycemia treatment. According to the above criteria, those who met the three and above criteria were diagnosed as MetS.

\section{Calculation formula for anthropometric indicators}

BMI, WHtR, ABSI and BRI were used in this study, and the calculation formulas were shown as below.

$$
\begin{aligned}
& \text { (1) } B M I=\frac{\text { weight }}{\text { height }^{2}} \\
& \text { (2) } \mathrm{WHtR}=\frac{W C}{h e i g h t} \\
& \text { (3) } A B S I=\frac{W C}{\left(\text { height }^{\frac{1}{2}} \times B M I^{\frac{2}{3}}\right)} \\
& \text { (4) } B R I=364.2-365.5 \sqrt{1-\frac{\left(\frac{W C}{2 \pi}\right)^{2}}{(0.5 \times h e i g h t)^{2}}}
\end{aligned}
$$

\section{Statistical analysis}

Epidata3.01 software was used to input the questionnaire and laboratory data. SPSS (statistical product and service solutions) version 23.0 software of IBM Company was applied to analyze the data. The continuous variables in accordance with the normal distribution were expressed by mean \pm standard deviation, and the quantitative data were compared by independent sample $t$-test. The standardized prevalence of MetS and its components was adjusted in the following formula, using the data of the sixth Chinese national population census. The WC was converted to a $\mathrm{z}$-score by this equation: $\left(\mathrm{WC}-\mathrm{WC}_{\text {mean }}\right) / \mathrm{WC} \mathrm{SD}$. BMI, WHtR, ABSI and BRI were also transformed to $\mathrm{z}$-scores by the same equation. The association between each $\mathrm{z}$-score and MetS was measured by the logistic analysis, and adjusted factors were age, gender, drinking and smoking conditions. Sex-specific zscore of these indicators would be transformed when conducting sex stratification logistic analysis, and the adjusted factors were age, drinking and smoking conditions. The z-score made the comparison meaningful because the unit change in the logistic regression analysis was different for the chosen anthropometric measures. The area under the receiver operating characteristic curve (AUROC) was the measurement to estimate the ability of each anthropometric indicator in predicting MetS, and the optimal value of each indicator was determined by the Youden's index. Delong test in the pROC package of $\mathrm{R}$ software version 3.6.1 was used to compare the area under different curves. $P$ value $<0.05$ was considered statistical significance. 
standed prevelance $=\frac{\text { Number of Chinese male } * \text { Male prevalence in Jiangsu }+ \text { Number of Chinese female } * \text { Female prevalence in Jiangsu }}{\text { Total population number of China }}$

\section{Results}

\section{General information of participants}

In this study, 8040 individuals were enrolled, including 3606 men (44.9\%) and 4434 women (55.1\%). As shown in Table 1, a significant difference was existed in education level between men and women. The average waist circumference of men was $86.17 \mathrm{~cm}$, which was higher than that of women's $81.71 \mathrm{~cm}(P<0.001)$. Average of WHtR in men was lower than in women, 0.51 to $0.52(P<0.001)$. The mean value of BMI was even between men and women. The proportion of smoking and drinking in men was higher than that in women (smoking: male $49.9 \%$ vs. female $7.2 \%$, drinking: male $49.4 \%$ vs. $7.2 \%$ ).

\section{Prevalence of MetS and its components in adult residents of Jiangsu Province}

The prevalence of MetS was 35.2\% in Jiangsu Province, and $34.8 \%$ after adjusted by information from the sixth Chinese national population census. The proportion of

Table 1 Basic information of research population

\begin{tabular}{|c|c|c|c|}
\hline \multirow[t]{2}{*}{ Variables } & \multirow{2}{*}{$\begin{array}{l}\text { Male (\%) } \\
N=3606\end{array}$} & \multirow{2}{*}{$\begin{array}{l}\text { Female (\%) } \\
N=4434\end{array}$} & \multirow{2}{*}{$\begin{array}{l}P \\
\text { value }\end{array}$} \\
\hline & & & \\
\hline Age & $54.73 \pm 15.12$ & $53.73 \pm 15.09$ & 0.003 \\
\hline$\leq 54$ & $1639(45.5)$ & $2205(49.7)$ & $<0.001$ \\
\hline$\geq 55$ & $1967(54.5)$ & $2229(50.3)$ & \\
\hline Education level $^{a}$ & & & $<0.001$ \\
\hline Primary school and below & $280(7.8)$ & $1019(23.0)$ & \\
\hline Middle school & $2439(67.7)$ & $2670(60.3)$ & \\
\hline University and above & $885(24.6)$ & $737(16.7)$ & \\
\hline WC (cm) & $86.17 \pm 16.23$ & $81.71 \pm 10.19$ & $<0.001$ \\
\hline $\mathrm{BMI}\left(\mathrm{kg} / \mathrm{m}^{2}\right)$ & $24.31 \pm 4.91$ & $24.27 \pm 3.97$ & 0.650 \\
\hline $\mathrm{WH} \mathrm{tR}$ & $0.51 \pm 0.059$ & $0.52 \pm 0.067$ & $<0.001$ \\
\hline Smoking & & & $<0.001$ \\
\hline no & $1801(50.1)$ & $4326(97.9)$ & \\
\hline yes & $1795(49.9)$ & $95(2.1)$ & \\
\hline Drinking & & & $<0.001$ \\
\hline no & $1825(50.6)$ & $4115(92.8)$ & \\
\hline yes & $1781(49.4)$ & $319(7.2)$ & \\
\hline$A B S I$ & $7.95 \pm 0.66$ & $7.83 \pm 0.68$ & $<0.001$ \\
\hline BRI & $3.67 \pm 1.16$ & $3.89 \pm 1.36$ & $<0.001$ \\
\hline
\end{tabular}

${ }^{a}$ Education level is not of all subjects

WC Waist circumference, BMI body mass index, WHtR waist-to-height ratio, $A B S I$ a body shape index, $B R I$ body roundness index central obesity (male/female WC > 85/80 cm) was 52.7\%, elevated triglycerides $(>1.70 \mathrm{mmol} / \mathrm{L})$ was $36.9 \%$, reduced HDL-C (male/female HDL-C $<1.0 / 1.30 \mathrm{mmol} / \mathrm{L}$ ) was $33.1 \%$, elevated blood pressure $(\geq 130 / 85 \mathrm{mmHg})$ was $51.5 \%$, and elevated fasting glucose (FPG $\geq 5.6$ $\mathrm{mmol} / \mathrm{L}$ ) was $26.1 \%$. The prevalence of MetS in women was $38.0 \%$, higher than $31.7 \%$ in men. Women were prone to have central obesity with a prevalence of $53.8 \%$ than men, which was $51.3 \%$. The prevalence of reduced HDL-C in women was $46.1 \%$, significantly higher than $17.1 \%$ in men, while the prevalence of elevated blood pressure was $47.5 \%$, lower than $56.5 \%$ in men. (For more details displayed in Fig. 1 and Table 2).

\section{Associations of five anthropometric measures with MetS and its components}

Table 3 demonstrated the associations of five anthropometric measures with MetS and its components. In the total population, after adjusted by age, gender, drinking, and smoking conditions, z-scores of WC, BMI, WHtR, ABSI and BRI were positively associated with MetS and most of its components (adjusted OR $>1$ ), while the association intensity of WC, WHtR and BRI with MetS was higher than that of BMI and ABSI. Sex stratification logistic analysis indicated that WC, WHtR and BRI sexspecific z-scores still had strong associations with MetS (all adjusted OR $>1$ ) in both male and female population after adjusting age, drinking and smoking conditions. In male population, WHtR z-score had the highest odds ratio in predicting Mets. If WHtR z-score increases by one unit, the risk of MetS would be affected by 3.82 times. The WC z-score increased by one unit, and the risk of MetS increased by 3.54 times in female. There were stronger associations between WC/WHtR/BRI z-score and elevated triglycerides and reduced HDL-C in both genders. BMI z-score had higher associations with elevated blood pressure and elevated fasting glucose in both genders.

ROC curve of five anthropometric indices to predict MetS In Table 4, the AUROC of different indicators for predicting the MetS in both male and female were compared. In male, the area under the curve of WC was 0.810 (95\% CI $=0.795-0.824)$, and the area under the curve of WHtR and BRI was the same, which was 0.800 (95\% CI $=0.785-0.815)$. In female, the area under the curve of WC was $0.801(95 \% \mathrm{CI}=0.788-0.814)$, and the 


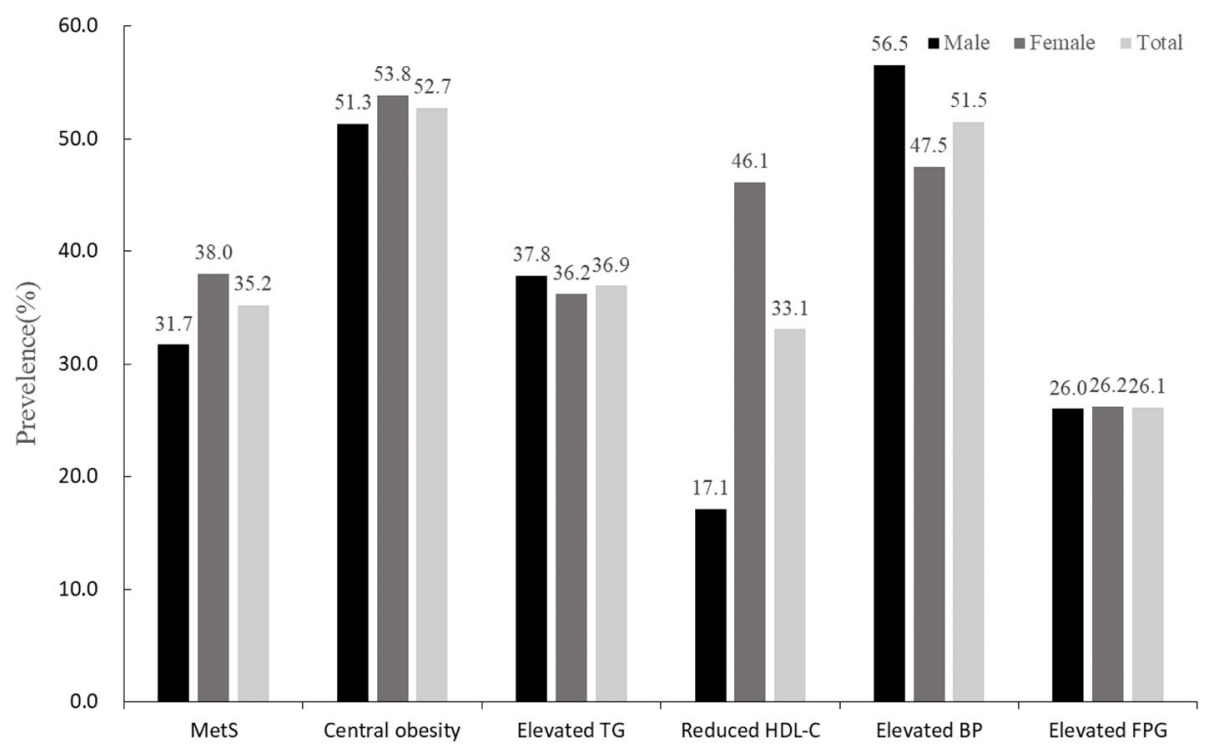

Fig. 1 Prevalence of MetS and its components in Jiangsu adult residents. Central obesity: male/female's waist circumference $\geq 85 / 80 \mathrm{~cm}$

area under the curve of WHtR and BRI was the same, which was $0.802(95 \% \mathrm{CI}=0.789-0.815)$. WC, WHtR and BRI had larger area under the ROC curve than BMI and ABSI in both genders after pairwise comparisons by the Delong test in supplementary Table S1 of Additional file 2 . WC in men had the largest area under the ROC curve, the area under the WC curve was significantly higher than the other four indicators, BMI, WHtR, ABSI and BRI $(Z$ value $=9.08,2.88,16.73,2.75$ respectively). Among women, WC, WHtR and BRI had the larger area under the ROC curve, which were 0.801 $(95 \% \mathrm{CI}=0.788-0.814), \quad 0.802(95 \% \mathrm{CI}=0.789-0.815)$ and $0.802(95 \% \mathrm{CI}=0.789-0.815)$, respectively. After the pairwise comparison of the Delong test, the area under the WC, WHtR and BRI were not significantly different.

Optimal cut-off values of WC, WHtR and BRI for predicting MetS were displayed in Table 5. In male, when the WC cut-off value was $85.25 \mathrm{~cm}$, the maximum Youden's index was 0.55 . The sensitivity was $88.1 \%$ and the specificity was $66.6 \%$. In female, when the WC cutoff value was 80.05 , the maximum Youden's index was 0.52 . The sensitivity was $85.9 \%$ and the specificity was
65.9\%. The optimal cut-off value of WHtR in male was 0.52 determined by the maximum Youden's index (0.48). The sensitivity was $81.0 \%$ and the specificity was $66.9 \%$. In female, when the WHtR cut-off value was 0.51 , the maximum Youden's index was 0.48 . The sensitivity was $76.9 \%$ and the specificity was $71.3 \%$. The optimal BRI cut-off value in male was 3.61 and the maximum Youden's index was 0.48 . The sensitivity was $81.0 \%$, the specificity was $66.9 \%$. In female, when the BRI cut-off value was 3.83 , the maximum Youden's index was 0.48 , and the sensitivity was $76.9 \%$, the specificity was $71.3 \%$.

\section{Discussions}

This study updated the condition of MetS and its components among Jiangsu adult residents in eastern China through a well-designed study and evaluated the ability of five non-invasive, low-cost and easily-calculated anthropometric measures, including WC, BMI, WHtR, ABSI and BRI, in predicting MetS. It turned out that, Jiangsu were at high burden of Mets and its components, and WC/WHtR/BRI had good regional representative predicting value for MetS in Jiangsu Province.

Table 2 Prevalence of MetS and its components in Jiangsu adult residents

\begin{tabular}{lllll}
\hline MetS components & Male (\%) & Female (\%) & $P$ value & Crude/standardized prevalence (\%) \\
\hline MetS & 31.7 & 38.0 & $<0.001$ & $35.2 / 34.8$ \\
Central obesity & 51.3 & 53.8 & 0.027 & $52.7 / 52.5$ \\
Elevated triglycerides & 37.8 & 36.2 & 0.138 & $36.9 / 37.0$ \\
Reduced HDL-C & 17.1 & 46.1 & $<0.001$ & $33.1 / 31.2$ \\
Elevated blood pressure & 56.5 & 47.5 & $<0.001$ & $51.5 / 52.1$ \\
Elevated fasting glucose & 26.0 & 26.2 & 0.835 & $26.1 / 26.1$ \\
\hline
\end{tabular}


Table 3 Associations of five anthropometric measures with MetS and its components

\begin{tabular}{|c|c|c|c|c|c|}
\hline MetS components & WC z-Score & BMI z-Score & WHtR z-Score & ABSI z-Score & BRI z-Score \\
\hline \multicolumn{6}{|l|}{ MetS } \\
\hline Adjusted OR & $3.66(3.42 \sim 3.92)$ & $2.74(2.57 \sim 2.92)$ & $3.38(3.16 \sim 3.61)$ & $1.63(1.55 \sim 1.72)$ & $3.27(3.06 \sim 3.50)$ \\
\hline Male adjusted OR & $3.79(3.41 \sim 4.22)$ & $3.02(2.73 \sim 3.35)$ & $3.82(3.42 \sim 4.27)$ & $1.71(1.58 \sim 1.86)$ & $3.76(3.37 \sim 4.21)$ \\
\hline Female adjusted OR & $3.54(3.23 \sim 3.88)$ & $2.55(2.36 \sim 2.76)$ & $3.10(2.85 \sim 3.37)$ & $1.56(1.45 \sim 1.67)$ & $2.98(2.74 \sim 3.24)$ \\
\hline \multicolumn{6}{|l|}{ Elevated triglycerides } \\
\hline Adjusted OR & $1.52(1.45 \sim 1.60)$ & $1.36(1.29 \sim 1.43)$ & $1.47(1.40 \sim 1.54)$ & $1.23(1.17 \sim 1.29)$ & $1.46(1.39 \sim 1.53)$ \\
\hline Male adjusted OR & $1.67(1.56 \sim 1.81)$ & $1.51(1.39 \sim 1.63)$ & $1.69(1.56 \sim 1.83)$ & $1.33(1.24 \sim 1.44)$ & $1.71(1.58 \sim 1.86)$ \\
\hline Female adjusted OR & $1.37(1.29 \sim 1.46)$ & $1.25(1.18 \sim 1.33)$ & $1.30(1.22 \sim 1.39)$ & $1.14(1.07 \sim 1.21)$ & $1.29(1.21 \sim 1.37)$ \\
\hline \multicolumn{6}{|l|}{ Reduced HDL-C } \\
\hline Adjusted OR & $1.59(1.51 \sim 1.68)$ & $1.49(1.41 \sim 1.57)$ & $1.73(1.61 \sim 1.85)$ & $1.15(1.10 \sim 1.21)$ & $1.51(1.44 \sim 1.59)$ \\
\hline Male adjusted OR & $1.80(1.64 \sim 1.97)$ & $1.74(1.58 \sim 1.92)$ & $1.83(1.66 \sim 2.01)$ & $1.26(1.15 \sim 1.38)$ & $1.80(1.64 \sim 1.98)$ \\
\hline Female adjusted OR & $1.49(1.39 \sim 1.59)$ & $1.39(1.31 \sim 1.48)$ & $1.40(1.32 \sim 1.49)$ & $1.10(1.04 \sim 1.17)$ & $1.39(1.31 \sim 1.48)$ \\
\hline \multicolumn{6}{|l|}{ Elevated blood pressure } \\
\hline Adjusted OR & $1.61(1.53 \sim 1.70)$ & $1.77(1.67 \sim 1.87)$ & $1.63(1.55 \sim 1.72)$ & $1.05(0.99 \sim 1.10)$ & $1.62(1.54 \sim 1.71)$ \\
\hline Male adjusted OR & $1.52(1.41 \sim 1.65)$ & $1.81(1.66 \sim 1.99)$ & $1.57(1.44 \sim 1.70)$ & $1.01(0.93 \sim 1.09)$ & $1.56(1.43 \sim 1.70)$ \\
\hline Female adjusted OR & $1.66(1.54 \sim 1.79)$ & $1.73(1.61 \sim 1.87)$ & $1.66(1.55 \sim 1.78)$ & $1.07(1.00 \sim 1.14)$ & $1.65(1.53 \sim 1.77)$ \\
\hline \multicolumn{6}{|l|}{ Elevated fasting glucose } \\
\hline Adjusted OR & $1.31(1.24 \sim 1.38)$ & $1.35(1.28 \sim 1.43)$ & $1.28(1.22 \sim 1.36)$ & $1.00(0.95 \sim 1.06)$ & $1.27(1.21 \sim 1.34)$ \\
\hline Male adjusted OR & $1.28(1.18 \sim 1.38)$ & $1.46(1.34 \sim 1.59)$ & $1.30(1.20 \sim 1.42)$ & $0.94(0.87 \sim 1.03)$ & $1.30(1.19 \sim 1.41)$ \\
\hline Female adjusted OR & $1.33(1.24 \sim 1.43)$ & $1.29(1.21 \sim 1.38)$ & $1.27(1.19 \sim 1.36)$ & $1.04(0.97 \sim 1.12)$ & $1.26(1.18 \sim 1.34)$ \\
\hline
\end{tabular}

$O R$ odds ratio, WC Waist circumference, $B M I$ body mass index, WHtR waist-to-height ratio, $A B S I$ a body shape index, BRI body roundness index, MetS metabolic syndrome

The anthropometric measures were converted to a $\mathrm{z}$-score using this equation:( $\left.\mathrm{X}-\mathrm{X}_{\text {mean }}\right) / \mathrm{X}_{\mathrm{SD}}$

Adjusted factors of whole population: age, gender (male/female), drinking (yes/no), smoking (yes/no);

Gender stratification adjusted factors: age, drinking (yes/no), smoking (yes/no)

We found that the prevalence of MetS among adult residents in Jiangsu Province was $35.2 \%$ in 2014. After standardized by the data from the sixth Chinese national census, the standardized prevalence was $34.8 \%$, which was higher than $33.9 \%$ in 2010 in China [16]. Under the same 2009 JIS diagnostic criteria, the crude prevalence of MetS in Jiangsu adults in 2010 was $38.9 \%$, and the standardized prevalence was $32.7 \%$ [17]. The prevalence of MetS in Jiangsu Province was basically stable over a fouryear period. The prevalence of central obesity was $52.7 \%$ and $52.5 \%$ after standardization. This was close to the central obesity prevalence of rural adult in Chinese Gansu Province, which was 53.18\% [18]. The JIS diagnostic criteria for central obesity (male/female's WC $\geq 85 / 80 \mathrm{~cm}$ ) is consistent with the widely-used standard criteria launched by Chinese officials and professions [19], which is capable of making results of different studies comparable.

The national surveillance data from 2010 to 2012 reported that MetS prevalence of women nationwide was slightly lower than that of men $(24.6 \%$ in men and $23.8 \%$ in women) [20]. However, the prevalence of MetS in women from Jiangsu was $38.0 \%$, which was higher than $31.7 \%$ of men. On the one hand, the obesity rate of women in Jiangsu Province (14.3\%) was higher than that of men (12.1\%). This discrepancy could be explained by the difference in body fat distribution and lifestyle habits between men and women. On the other hand, the prevalence of reduced HDL-C in women was $46.1 \%$, which was significantly higher than $17.1 \%$ of men. Diagnostic

Table 4 Area under the ROC $(95 \% \mathrm{Cl})$ for the anthropometric indicators and MetS

\begin{tabular}{llllll}
\hline & WC & BMl & WHtR & ABSI & BRI \\
\hline Whole population & $0.787(0.776-0.797)$ & $0.736(0.725-0.748)$ & $0.803(0.793-0.812)$ & $0.656(0.644-0.668)$ & $0.803(0.793-0.812)$ \\
Male & $0.810(0.795-0.824)$ & $0.741(0.724-0.758)$ & $0.800(0.785-0.815)$ & $0.665(0.646-0.683)$ & $0.800(0.785-0.815)$ \\
Female & $0.801(0.788-0.814)$ & $0.735(0.720-0.750)$ & $0.802(0.789-0.815)$ & $0.660(0.644-0.676)$ & $0.802(0.789-0.815)$
\end{tabular}

WC Waist circumference, BMI body mass index, WHtR waist-to-height ratio, ABSI a body shape index, BRI body roundness index, MetS metabolic syndrome 
Table 5 Optimal cut-off points of WC, WHtR and BRI for predicting MetS

\begin{tabular}{lllll}
\hline & Optimal cut-off points & Sensitivity (\%) & Specificity (\%) & Youden's index \\
\hline WC & & & & 66.6 \\
Male & 85.25 & 88.1 & 65.9 & 0.55 \\
$\quad$ Female & 80.05 & 85.9 & & 0.52 \\
WHtR & & & 66.9 & 0.48 \\
Male & 0.52 & 81.0 & 71.3 & 0.48 \\
Female & 0.51 & 76.9 & & 0.48 \\
BRI & & & 66.9 & 0.48 \\
Male & 3.61 & 81.0 & 71.3 & \\
Female & 3.83 & 76.9 & & \\
\hline
\end{tabular}

WC Waist circumference, WHtR waist-to-height ratio, BRI body roundness index, MetS metabolic syndrome

criteria of reduced HDL-C between men and women was diverse. Adult Treatment Panel III of National Cholesterol Education Program (NCEP-ATP III) in 2005 defined the reduced HDL-C in male/female $<1.04$ $\mathrm{mmol} / \mathrm{L} / 1.30 \mathrm{mmol} / \mathrm{L} \quad$ [21]. International Diabetes Federation (IDF) in 2005 illuminated that reduced HDL$\mathrm{C}$ in male/female was $<1.03 \mathrm{mmol} / \mathrm{L} / 1.29 \mathrm{mmol} / \mathrm{L}$ [22].

Notably, positive associations were found between WC, BMI, WHtR, ABSI, BRI z-scores and MetS and its components. WC, WHtR and BRI z-scores had stronger associations than BMI and ABSI with MetS both in male and female population. After stratified by gender, WC had the largest area under the ROC curve of 0.810 in men, which was higher than WHtR/BRI of 0.800 . Among women, WHtR/BRI had the largest area under the ROC curve, which was 0.802 , while the area under the WC curve had no significant difference with WHtR/ BRI. The ROC curve of WHtR and BRI was overlapped and the area as well 95\% confidence intervals under each curve was the same, seen in the Fig. 2. This indicated that WHtR and BRI had same predictive abilities in MetS. A study conducted by Zhang et al., also compared WHtR and BRI with MetS in Chinese with same area under ROC curve in WHtR and BRI [5]. These results revealed similar abilities of WHtR and BRI in predicting MetS.

WC, as one of the key diagnostic components of MetS, showed the good predictive value, and the optimal cutoff values were close to the diagnostic criteria for central obesity. WC has been used as a representative marker for central obesity and a number of researchers have found that WC was a superior predictor compared to

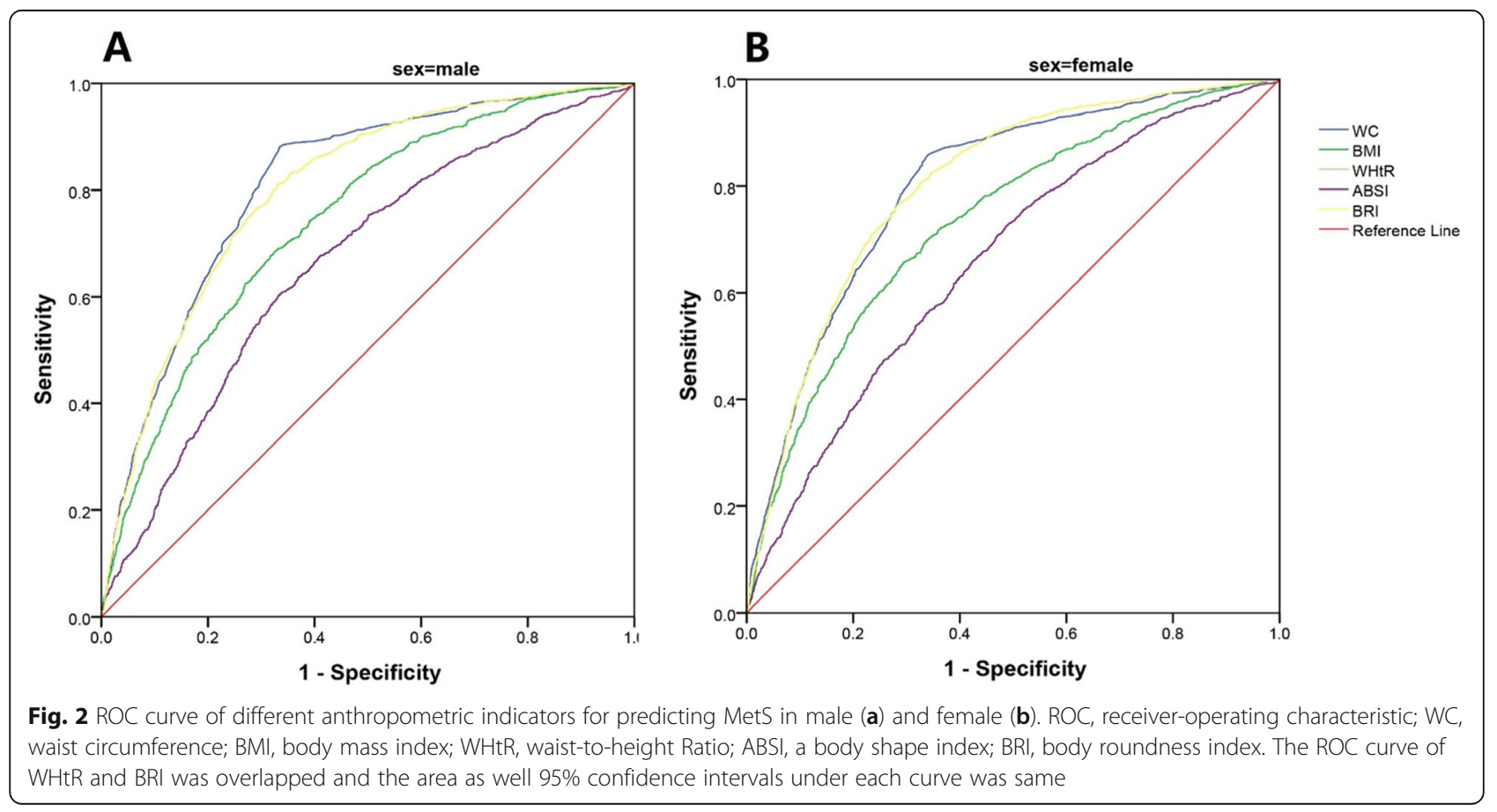


other anthropometric indices for MetS and cardiometabolic risk factors [23, 24]. Previous studies showed that WHtR can predict MetS superiorly to BMI [25]. WHtR is better in predicting MetS because it takes height into consideration and reliably reflected central obesity. Other study concluded that the WHtR $\geq 0.50$ was more strongly associated with metabolic syndrome in Chinese [26], which is consistent with optimal cutoff value of WHtR in our study (0.52 in male and 0.51 in female). BRI as a newer index, was superior to ABSI in predicting the risk of cardiovascular diseases, although there was a positive association between ABSI and premature death [27]. As to the MetS, the results of two studies in northern China revealed that the predictive ability of BRI was also higher than ABSI in predicting the metabolic disorder of diabetes $[28,29]$. A study in Peruvian adults found that BRI was better at predicting MetS than BMI [12]. Optimal BRI cutoff for undiagnosed diabetes was 3.7 [28], while in Chinese adults, the optimal cutoff of BRI for the diagnosis of MetS was 3.547 in men and 3.179 in women [5]. These results were similar with our study and showed the valuable potentials of these anthropometric measures to predict MetS and cardiovascular diseases. WC, WHtR and BRI seemed to have good value in predicting Mets in Jiangsu adults. In view of MetS and its components are high risk factors for cardiovascular diseases, the discover of indicators such as WC, WHtR and BRI to identify MetS with good predictive power and value, are exceedingly necessary.

We acknowledge that this study has some limitations. First, this is a cross-sectional study and relevant findings in this study should be verified in a well-designed cohort study. Second, under different diagnostic criteria, the prevalence of MetS will be diverse, so we compare the prevalence of MetS in Jiangsu Province using the latest and internationally recognized JIS standard. Third, these anthropometric measures are derivative indices calculated based on height, weight and waist circumference, therefore, in the diagnosis and prediction of MetS in the Chinese population, it is still worth further studying and evaluating different algorithms to find better anthropometric indices.

\section{Conclusions}

It turned out that MetS has become one of the major chronic diseases in Jiangsu Province, with 31.7 and $38.0 \%$ prevalence in male and female respectively. WC was better than other indices in predicting MetS among male population. While in female population, WC, WHtR and BRI had superior abilities than BMI/ABSI in predicting MetS. There are more clinical and practical meanings in applying anthropometric indices to the diagnosis of MetS.

\section{Supplementary information}

Supplementary information accompanies this paper at https://doi.org/10. 1186/s12889-020-09423-9.

Additional file 1. STROBE Statement. Checklist of items that should be included in reports of cross-sectional studies.

Additional file 2: Supplementary Table S1. Pairwise comparison between WC, BMI, WHtR, ABSI and BRI of the AUROC in predicting metabolic syndrome by the Delong test.

\section{Abbreviations}

MetS: Metabolic syndrome; WC: Waist circumference; WHtR: Waist-to-height ratio; ABSI: A body shape index; BRI: Body roundness index; TG: Triglyceride; HDL-C: High-density lipoprotein; BMI: Body mass index; FPG: Fasting plasma glucose; SBP: Systolic blood pressure; DBP: Diastolic blood pressure; AUROC: Area under the receiver operating characteristic curve; JIS: Joint Interim Statement; NCEP-ATP III: Adult Treatment Panel III of National Cholesterol Education Program; IDF: International Diabetes Federation

\section{Acknowledgments}

The authors are grateful to the Nanjing Medical University and Southeast University for the support in study design and field work.

\section{Authors' contributions}

Y.D. participated in the conceptualization and methodology of the study. T.T., J.X.Z. carried out the surveys and experiments. T.T., Q.R.Z. contributed to the acquisition and interpretation of data. T.T., W.X. and Y.Y.W. performed the statistical analysis. T.T. and J.X.Z. wrote the manuscript and Tables. Y.D. prepared the figures. All authors read and approved the final manuscript. All authors have read and agreed to the final version of the manuscript.

\section{Funding}

The authors declare no funding sources.

\section{Availability of data and materials}

The datasets used and/or analyzed during the current study are available from the corresponding author on reasonable request.

\section{Ethics approval and consent to participate}

This study was approved by the ethics committee of the Jiangsu provincial center for disease control and prevention, and reference number was No. JSCDC2014236. All participants had signed the informed consent on this study.

Consent for publication

Not applicable.

\section{Competing interests}

The authors declare no conflict of interest.

Received: 6 March 2020 Accepted: 23 August 2020

Published online: 31 August 2020

\section{References}

1. Cornier MA, Dabelea D, Hernandez TL, Lindstrom RC, Steig AJ, Stob NR, Van Pelt RE, Wang H, Eckel RH. The metabolic syndrome. Endocr Rev. 2008;29(7): 777-822.

2. Samson SL, Garber AJ. Metabolic syndrome [J]. Endocrinol Metab Clin N Am. 2014;43(1):1-23.

3. Grundy SM. Metabolic syndrome: a multiplex cardiovascular risk factor. J Clin Endocrinol Metab. 2007:92:399-404.

4. Gallagher EJ, LeRoith D, Karnieli E. The metabolic syndrome--from insulin resistance to obesity and diabetes. Endocrinol Metab Clin N Am. 2008;37(3): 559-79 vii.

5. Zhang J, Zhu W, Qiu L, Huang L, Fang L. Sex- and age-specific optimal anthropometric indices as screening tools for metabolic syndrome in Chinese adults. Int J Endocrinol. 2018;2018:1067603.

6. Krakauer NY, Krakauer JC. A new body shape index predicts mortality hazard independently of body mass index. PLoS One. 2012;7(7):e39504. 
7. Thomas DM, Bredlau C, Bosy-Westphal A, et al. Relationships between body roundness with body fat and visceral adipose tissue emerging from a new geometrical model. Obesity (Silver Spring). 2013;21(11):2264-71.

8. Fang $\mathrm{H}$, Berg $\mathrm{E}$, Cheng $\mathrm{X}$, Shen W. How to best assess abdominal obesity. Curr Opin Clin Nutr Metab Care. 2018;21(5):360-5.

9. Sayeed MA, Mahtab H, Latif ZA, Khanam PA, Ahsan KA, Banu A, et al. Waistto-height ratio is a better obesity index than body mass index and waist-tohip ratio for predicting diabetes, hypertension and lipidemia. Bangladesh Med Res Counc Bull. 2003;29(1):1-10.

10. Savva SC, Lamnisos D, Kafatos AG. Predicting cardiometabolic risk: waist-to-height ratio or BMI. A meta-analysis. Diabetes Metab Syndr Obes. 2013;6:403-19.

11. Bawadi H, Abouwatfa M, Alsaeed S, et al. Body Shape Index Is a Stronger Predictor of Diabetes. Nutrients. 2019:11(5).

12. Stefanescu A, Revilla L, Lopez T, et al. Using a body shape index (ABSI) and body roundness index (BRI) to predict risk of metabolic syndrome in Peruvian adults. J Int Med Res. 2019;300060519848854.

13. Wang H, Liu A, Zhao T, Gong X, Pang T, Zhou Y, et al. Comparison of anthropometric indices for predicting the risk of metabolic syndrome and its components in Chinese adults: a prospective, longitudinal study. BMJ Open. 2017;7(9):e016062.

14. Chobanian AV, Bakris GL, Black HR, Cushman WC, Green LA, Izzo JL Jr, et al. The seventh report of the joint National Committee on prevention, detection, evaluation, and treatment of high blood pressure: the JNC 7 report. JAMA. 2003;289(19):2560-72.

15. Alberti KG, Eckel RH, Grundy SM, Zimmet PZ, Cleeman JI, Donato KA, Fruchart JC, James WP, Loria CM, Smith SC. Harmonizing the metabolic syndrome: a joint interim statement of the international diabetes federation task force on epidemiology and prevention; National Heart, Lung, and Blood Institute; American Heart Association; world heart federation; international atherosclerosis society; and International Association for the Study of obesity. Circulation. 2009;120(16):1640-5.

16. Lu J, Wang L, Li M, et al. Metabolic syndrome among adults in China: the 2010 China noncommunicable disease surveillance. J Clin Endocrinol Metab. 2017; 102(2):507-15.

17. Tao R, Wu M, Qin Y, Su J, Zhang Y, Liu S, et al. Epidemiological characteristics of metabolic syndrome and comparison between its different diagnostic criteria in adults of Jiangsu Province. J Jilin Univ (Medicine Edition). 2015;41(01):181-9.

18. Gao W, Qiao X, Wang Y, Wan L, Wang Z, Wang X, et al. The interactive Association of General Obesity and Central Obesity with prevalent hypertension in rural Lanzhou. China PLoS One. 2016;11(10):e0164409.

19. Chen C, Lu FC. Department of Disease Control Ministry of Health, PR China. The guidelines for prevention and control of overweight and obesity in Chinese adults. Biomed Environ Sci. 2004;17(Suppl):1-36.

20. Li Y, Zhao L, Yu D, et al. Metabolic syndrome prevalence and its risk factors among adults in China: a nationally representative cross-sectional study [J]. PLoS One. 2018;13(6):e0199293. https://doi.org/10.1371/journal.pone.0199293.

21. Grundy SM, Cleeman JI, Daniels SR, Donato KA, Eckel RH, Franklin BA, Gordon DJ, Krauss RM, Savage PJ, Smith SC, Spertus JA, Costa F. Diagnosis and management of the metabolic syndrome: an American Heart Association/National Heart, Lung, and Blood Institute scientific statement. Curr Opin Cardiol. 2006;21(1):1-6.

22. Alberti KG, Zimmet P, Shaw J. The metabolic syndrome--a new worldwide definition. Lancet. 2005;366(9491):1059-62.

23. Perona JS, Schmidt RJ, Ramírez-Vélez R, Correa-Rodríguez M, FernándezAparicio Á, González-Jiménez E. Waist circumference and abdominal volume index are the strongest anthropometric discriminators of metabolic syndrome in Spanish adolescents. Eur J Clin Investig. 2019;49(3):e13060.

24. Choi JR, Ahn SV, Kim JY, Koh SB, Choi EH, Lee GY, et al. Comparison of various anthropometric indices for the identification of a predictor of incident hypertension: the ARIRANG study. J Hum Hypertens. 2018;32(4): 294-300.

25. Zhu Q, Shen F, Ye T, Zhou Q, Deng H, Gu X. Waist-to-height ratio is an appropriate index for identifying cardiometabolic risk in Chinese individuals with normal body mass index and waist circumference. J Diabetes. 2014; 6(6):527-34

26. Chen BD, Yang YN, Ma YT, Pan S, He CH, Liu F, et al. Waist-to-height ratio and triglycerides/high-density lipoprotein cholesterol were the optimal predictors of metabolic syndrome in Uighur men and women in Xinjiang, China. Metab Syndr Relat Disord. 2015;13(5):214-20.
27. Maessen MF, Eijsvogels TM, Verheggen RJ, et al. Entering a new era of body indices: the feasibility of a body shape index and body roundness index to identify cardiovascular health status. PLoS One. 2014;9(9):e107212.

28. Zhao Q, Zhang K, Li Y, et al. Capacity of a body shape index and body roundness index to identify diabetes mellitus in Han Chinese people in Northeast China: a cross-sectional study. Diabet Med. 2018;35(11):1580-7.

29. Chang $Y$, Guo X, Chen $Y$, et al. A body shape index and body roundness index: two new body indices to identify diabetes mellitus among rural populations in Northeast China. BMC Public Health. 2015;15:794.

\section{Publisher's Note}

Springer Nature remains neutral with regard to jurisdictional claims in published maps and institutional affiliations.
Ready to submit your research? Choose BMC and benefit from:

- fast, convenient online submission

- thorough peer review by experienced researchers in your field

- rapid publication on acceptance

- support for research data, including large and complex data types

- gold Open Access which fosters wider collaboration and increased citations

- maximum visibility for your research: over $100 \mathrm{M}$ website views per year

At BMC, research is always in progress.

Learn more biomedcentral.com/submissions 